\title{
PRODUTIVIDADE DE FITOMASSA E RELAÇÃO C/N DE MONOCULTIVOS E CONSÓRCIOS DE GUANDU-ANÃO, MILHETO E SORGO EM TRÊS ÉPOCAS DE CORTE $\left({ }^{1}\right)$
}

\author{
CÁSSIO LOUREIRO CALVO $\left({ }^{2}\right)$; JOSÉ SALVADOR SIMONETI FOLONI $\left({ }^{*}\right)$; \\ SANDRO ROBERTO BRANCALIÃO $\left({ }^{4}\right)$
}

\begin{abstract}
RESUMO
Objetivou-se com este trabalho avaliar o rendimento de fitomassa, o acúmulo de $\mathrm{N}$ e a relação C/ $\mathrm{N}$ da matéria vegetal produzida em monocultivos e consórcios de guandu-anão (Cajanus cajan), sorgo (Sorghum bicolor) e milheto (Pennisetum glaucum), em três épocas de corte. O experimento foi realizado em Presidente Prudente (SP), entre março e julho de 2006. Utilizou-se o delineamento experimental em blocos aos acaso, no esquema fatorial, com os seguintes tratamentos: monocultivos de sorgo, guanduanão e milheto, e consórcios de sorgo + guandu-anão, milheto + guandu-anão e milheto + sorgo, com épocas de corte aos 30,60 e 90 dias após a semeadura. O milheto é mais expressivo quanto à rapidez de crescimento nos primeiros 60 dias após a semeadura, de tal forma que domina o guandu-anão e o sorgo em consórcio, e produz mais fitomassa nas culturas consorciadas do que em monocultivo. O corte ou manejo das culturas consorciadas de milheto + guandu-anão e sorgo + guandu-anão no ambiente de safrinha, deve ser realizado aos 60 e 90 dias após a semeadura, respectivamente. Na consorciação de sorgo + guandu-anão há maior sincronismo de crescimento entre ambas as espécies, o que favorece o equilíbrio na composição da fitomassa da cultura de cobertura. Nos consórcios de guandu-anão com as gramíneas ocorrem maiores acúmulos de $\mathrm{N}$ nas palhadas do que no monocultivo de guandu-anão, e menores valores de relação $\mathrm{C} / \mathrm{N}$ em relação aos monocultivos de milheto e sorgo.
\end{abstract}

Palavras-chave: planta de cobertura, adubo verde, sistema plantio direto.

\author{
ABSTRACT \\ PHYTOMASS YIELD AND C/N RELATION OF SINGLE CROPS AND INTERCROPS \\ OF PEGEON PEA, SORGHUM AND PEAR MILLET IN THREE CUT MANAGEMENT TIMES
}

The objective of the present study was to evaluate drymass performance, nitrogen (N) accumulation, and $\mathrm{C} / \mathrm{N}$ ratio of pigeon pea, sorghum, and millet grown as mono- or multiple cropping. Dry mass sampling was undertaken at three different seasons. The experiment was set up in fatorial randomised plot design in Presidente Prudente, State of Sao Paulo between March and July 2006. Treatments were as follows: monocropping of sorghum, pigeon pea, and millet; multiple cropping of sorghum + pigeon pea, millet + pigeon pea, and millet + sorghum. The three cutting seasons for plant top dry mass measurements were: 30,60, and 90 days after sowing time. In the first 60 days after sowing time, millet showed higher growth than pigeon pea and sorghum thus resulting in higher dry mass yield in the

( $\left.{ }^{1}\right)$ Parte da dissertação de mestrado do primeiro autor, apresentada ao Curso de Pós-Graduação em Agronomia - Produção Vegetal, Universidade do Oeste Paulista. Recebido para publicação em 7 de dezembro de 2007 e aceito em 5 de novembro de 2009.

$\left(^{2}\right)$ Escola Estadual Técnica Agropecuária de Segundo Grau “Deputado Francisco Franco". Caixa Postal 061, 19600-000 Rancharia (SP). E-mail: cassio_calvo@hotmail.com.

$\left(^{3}\right)$ Área de Fitotecnia, IAPAR. Caixa Postal 481, 86001-970 Londrina (PR). E-mail: sfoloni@iapar.br $\left(^{*}\right)$ Autor correspondente.

$\left({ }^{4}\right)$ Centro de Solos e Recursos Ambientais, IAC-APTA. Caixa Postal 28, 13020-902 Campinas (SP). E-mail: brancaliao@iac.sp.gov.br 
multiple cropping than alone. The cutting of the tops of millet + pigeon pea and sorghum + pigeon pea at the end of the summer rainy season ('safrinha') shall be conducted 60 and 90 days after sowing time, respectively. Multiple cropping of sorghum + pigeon pea show higher growth synchronicity of the two crops favouring balanced dry mass composition of the cover crops. Multiple croppings of pigeon pea with grass plants showed higher $\mathrm{N}$ accumulation in the plant residues than pigeon pea monocropping. However, multiple croppings of pigeon pea with grass plants showed lower $\mathrm{C} / \mathrm{N}$ ratio than monocropping of millet or sorghum.

key words: cover crop, green manure, no-tillage.

\section{INTRODUÇÃO}

Uma das estratégias para minimizar perdas de nutrientes em sistemas de produção agrícolas, é manter as áreas constantemente vegetadas. Segundo BORKERT et al. (2003), no caso do nitrogênio (N), que é muito móvel no solo e volatiliza-se facilmente, estimase que de $60 \%$ a $70 \%$ do total disponível nos sistemas de produção estejam contidos na biomassa vegetal, e a reciclagem promovida pelas espécies de cobertura é muito expressiva no suprimento nutricional das culturas comerciais.

A disponibilização de $\mathrm{N}$ para as lavouras depende da natureza e quantidade do nutriente no solo, da relação carbono/nitrogênio $(\mathrm{C} / \mathrm{N})$ dos restos vegetais, do grau de contato da palhada com os colóides do solo, assim como das condições climáticas (Silgram e Shepherd, 1999). Portanto, no que se refere à participação das plantas de cobertura, de acordo com Oliveira et al. (2002), é primordial escolher espécies com elevada capacidade de acumular $\mathrm{N}$ na fitomassa, seja pela fixação de $\mathrm{N}_{2}$ atmosférico, como no caso das leguminosas, seja pela absorção do nutriente no solo, ou por ambas em conjunto.

As gramíneas tropicais - milheto e sorgo - são amplamente utilizadas na entressafra das culturas de verão no Brasil Central, principalmente pela alta adaptabilidade à deficiência hídrica, elevada produção de fitomassa e grande capacidade de reciclar nutrientes (NeTTO, 1998; Portugal et al., 2003; Pereira Filho et al., 2005). Em contrapartida, as gramíneas de maneira geral apresentam grande demanda por N (CANTARELla et al., 1997), e possuem relação $\mathrm{C} / \mathrm{N}$ da palhada relativamente elevada quando comparadas às leguminosas (AMBROSANo et al., 1996).

De acordo com Moreira e Siqueira (2002), na presença de fitomassa com concentração de $\mathrm{N}$ alta e, consequentemente, relação $\mathrm{C} / \mathrm{N}$ baixa, como das leguminosas de maneira geral, a demanda por $\mathrm{N}$ dos microrganismos no processo de decomposição é satisfeita rapidamente, e o $\mathrm{N}$ em excesso passa a ser liberado rapidamente no solo. Por outro lado, se a concentração de $\mathrm{N}$ dos resíduos vegetais for baixa (relação $\mathrm{C} / \mathrm{N}$ alta), a quantidade de $\mathrm{N}$ mineralizado não é suficiente para atender a demanda dos microorganismos, os quais passam a imobilizar o $\mathrm{N}$ mineral disponível no solo, comprometendo a nutrição nitrogenada das lavouras.

No que diz respeito à manutenção da palhada para viabilizar o sistema plantio direto (SPD), geralmente, as gramíneas contribuem com quantidades relativamente elevadas de fitomassa, caracterizadas pela alta relação $\mathrm{C} / \mathrm{N}$, o que aumenta a persistência da cobertura do solo ao longo do tempo (ANDREOla et al., 2000). Por outro lado, as leguminosas, por fixarem o $\mathrm{N}$ atmosférico, possuem altos teores de $\mathrm{N}$ na matéria vegetal, e os restos vegetais geralmente têm baixa relação $\mathrm{C} / \mathrm{N}$, com decomposição relativamente acelerada, promovendo pequena cobertura do solo e prejudicando o manejo conservacionista (Perin et al., 2004).

Assim, vários trabalhos têm sido desenvolvidos, principalmente no Sul do Brasil, para aprimorar a técnica de cultivos consorciados de gramíneas e leguminosas de cobertura, com o objetivo de produzir palhadas com disponibilização de $\mathrm{N}$ relativamente maior, sem comprometer a proteção do solo (AMADo et al., 2000; Giacomini et al., 2004; Teixeira et al., 2005). De acordo com Giacomini et al. (2004), o consórcio entre espécies de cobertura visa produzir fitomassa com relação C/ $\mathrm{N}$ intermediária em relação aos monocultivos, proporcionando cobertura do solo por mais tempo e melhor sincronia entre oferta e demanda de $\mathrm{N}$ para as culturas comerciais.

No entanto, é preciso que haja compatibilidade em termos de desenvolvimento vegetal entre as espécies a serem utilizadas no consórcio, pois as gramíneas tropicais geralmente têm maior capacidade fotossintética para crescer (TAIZ e ZeIGer, 2002), ao passo que as leguminosas possuem grande habilidade para incorporar $\mathrm{N}$ ao sistema de produção (Pimentel, 1998).

Objetivou-se com este trabalho avaliar o rendimento de fitomassa, o acúmulo de $\mathrm{N}$ e a relação $\mathrm{C} / \mathrm{N}$ da matéria vegetal produzida em monocultivos e consórcios de guandu-anão, sorgo e milheto, em três épocas de corte. 


\section{MATERIAL E MÉTODOS}

O experimento foi realizado em Presidente Prudente (SP), durante os meses de março a julho de 2006. O solo foi classificado como Argissolo Vermelho distroférrico (EMBRAPA, 1999), com relevo suave ondulado e boa drenagem. A localização geográfica da área experimental é de $22^{\circ} 07^{\prime} 05^{\prime \prime} \mathrm{Sul}, 51^{\circ} 27^{\prime} 01^{\prime \prime}$ Oeste e $430 \mathrm{~m}$ da altitude. Na figura 1 são apresentados dados de precipitação pluvial e de temperatura ocorridos durante o período de realização do experimento.

A amostragem do solo foi feita em janeiro de 2006, na camada de 0 a $20 \mathrm{~cm}$ de profundidade, para caracterização de atributos químicos (RAIJ et al., 2001) e granulométricos (EMBRAPA, 1997), cujos resultados foram: $\mathrm{pH}\left(\mathrm{CaCl}_{2} 0,01 \mathrm{~mol} \mathrm{~L}^{-1}\right) 5,9 ; 18 \mathrm{~g}$ $\mathrm{dm}^{-3}$ de MO; $16 \mathrm{mg} \mathrm{dm}^{-3}$ de $\mathrm{P}_{\text {resina }} ; 27 \mathrm{mmol}_{\mathrm{c}} \mathrm{dm}^{-3}$ de $\mathrm{H}+\mathrm{Al} ; 1,2 \mathrm{mmol}_{\mathrm{c}} \mathrm{dm}^{-3}$ de $\mathrm{K} ; 38 \mathrm{mmol}_{\mathrm{c}} \mathrm{dm}^{-3}$ de Ca; $12 \mathrm{mmol}_{\mathrm{c}} \mathrm{dm}^{-3}$ de Mg; $52 \mathrm{mmol}_{\mathrm{c}} \mathrm{dm}^{-3}$ de SB; 69 $\mathrm{mmol}_{\mathrm{c}} \mathrm{dm}^{-3}$ de CTC; saturação por bases de $74 \%$; $740 \mathrm{~g} \mathrm{~kg}^{-1}$ de areia; $80 \mathrm{~g} \mathrm{~kg}^{-1}$ de silte; $180 \mathrm{~g} \mathrm{~kg}^{-1} \mathrm{de}$ argila.

Em 2/3/06, após gradagem com aradora e niveladora na área experimental, foram demarcados os sulcos de semeadura espaçados de 0,40 m, com equipamento motomecanizado, adicionando-se $200 \mathrm{~kg}$ ha ${ }^{-1}$ do adubo formulado 08-28-16. Esta adubação de semeadura foi realizada com base na recomendação de CAntarella et al. (1997) para a cultura do sorgo, considerando-se o nível de produtividade de 30 a 40 t ha ${ }^{-1}$ de matéria verde.

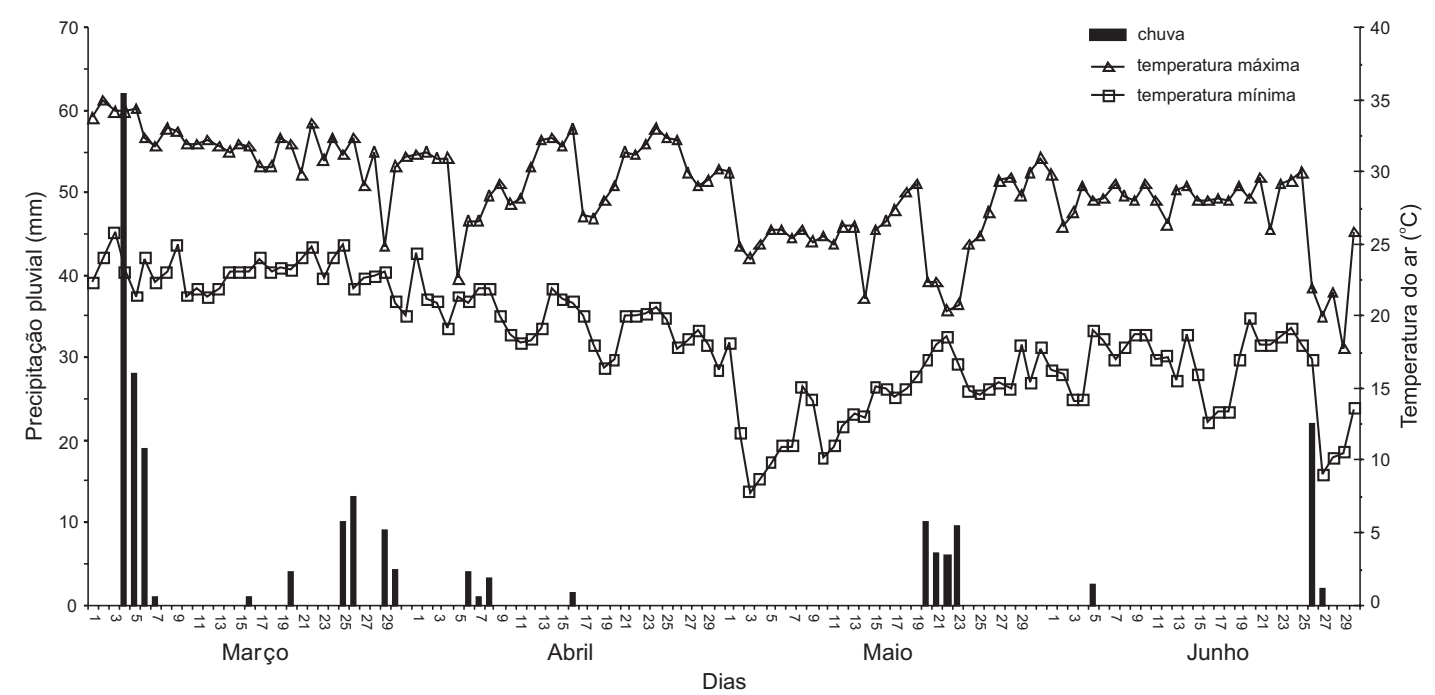

Figura 1. Precipitação pluvial diária, e temperaturas máximas e mínimas diárias do ar ocorridas no período de março a junho de 2006 na área experimental, em Presidente Prudente (SP).

Em seguida, as espécies de cobertura foram semeadas manualmente, em diferentes densidades conforme as recomendações de CALEgARI (1995) para o guandu-anão (Cajanus CaJAN, CV. ANão), Pereira Filho et al. (2005) para o milheto (Penissetum GLAUCum, cv. BN-2) е Ribas (2006) para o sorgo (Sorghum bicolor, cv. BRS-800).

O delineamento experimental foi em blocos completos casualizados, com quatro repetições, no esquema fatorial $6 \times 3$. Os tratamentos foram constituídos da seguinte forma: monocultivos de sorgo, guandu-anão e milheto, e consórcios de sorgo + guandu-anão, milheto + guandu-anão e milheto + sorgo; submetidos ao corte nos estádios de 30, 60 e 90 dias após a semeadura (DAS).

As parcelas experimentais foram constituídas de 8 linhas de semeadura com $4 \mathrm{~m}$ de comprimento, sendo avaliadas somente as 4 linhas centrais, considerandose como bordadura $1 \mathrm{~m}$ nas extremidades de cada linha. Nos monocultivos, semearam-se as espécies nas oito linhas seguidas, e nos consórcios, as semeaduras foram feitas de maneira intercalada, ou seja, linhas alternadas para cada espécie.

Aos 17 e 30 DAS realizaram-se capinas manuais no experimento, e nesta última operação foram determinados os estandes de plantas, com quatro repetições de $2 \mathrm{~m}$ de linha de semeadura, escolhidas aleatoriamente na área útil das parcelas. Nesta avaliação, fez-se a contagem de todos os caules desenvolvidos, e calcularam-se as médias com seus respectivos desvios-padrão: $21,32( \pm 4,68)$ caules de sorgo por metro de linha de semeadura, $14,88( \pm 3,25)$ caules de guandu-anão por metro de linha e 27,36 ( \pm 8,36 ) caules de milheto por metro de linha. 
Para realizar as avaliações das fitomassas aos 30, 60 e 90 DAS, foram coletadas as plantas contidas em 4 subamostras de $1 \mathrm{~m}$ de linha de semeadura, escolhidas aleatoriamente na área útil das parcelas. A parte aérea das plantas foi cortada rente à superfície do solo, e pesou-se todo o material vegetal coletado no campo, separadamente para cada espécie, tanto nos tratamentos de monocultivos como nos consórcios. Imediatamente após as pesagens das amostras, foram retiradas alíquotas para cada espécie separadamente, que foram acondicionadas em sacos de plástico vedados, para serem submetidas à pesagem e secagem em estufa de aeração forçada a $60^{\circ} \mathrm{C}$, até atingirem massa constante, permitindo calcular o teor de água e a produtividade de fitomassa seca para cada espécie.

Após as pesagens e retiradas das alíquotas, as amostras de fitomassa coletadas nos tratamentos de monocultivos e de consórcios foram secadas ao ar, picadas manualmente e passadas em triturador mecânico. Em seguida, para os tratamentos de culturas consorciadas, fez-se uma homogeneização manual das amostras das diferentes espécies, utilizando-se todo o material vegetal coletado no campo, para que fosse possível manter a proporcionalidade na composição da fitomassa a ser analisada.

Alíquotas do material triturado e, ou homogeneizado das amostras, foram submetidas à secagem controlada em estufa de aeração forçada a $60{ }^{\circ} \mathrm{C}$, até atingirem massa constante, e fez-se nova moagem com equipamento padrão, para posteriores determinações dos teores de N (Malavolta et al., 1997) e de C (Tedesco et al., 1995). Deste modo, foi possível calcular os acúmulos de $\mathrm{N}$ e as relações $\mathrm{C} / \mathrm{N}$ das palhadas produzidas nos monocultivos e nos consórcios.

Os resultados foram submetidos à análise de variância, e as características com níveis de significância de até $5 \%$ pelo teste $\mathrm{F}$, tiveram as médias dos tratamentos comparadas pelo teste Tukey a 5\% de significância.

\section{RESULTADOS E DISCUSSÃO}

A análise de variância revelou que houve efeito significativo das culturas de cobertura (c), das épocas de corte (e) e da interação c x e sobre todas as características avaliadas.

O crescimento inicial do milheto foi bastante expressivo e confirmou a superioridade na capacidade de ocupação do solo, demonstrada por SUZUKI e Alves (2006), como pode ser observado na tabela 1 para a fitomassa produzida aos 30 DAS. De acordo com Cazetta et al. (2005), o melhor desempenho das gramíneas de cobertura para produção de palhada no sistema plantio direto (SPD) está relacionado, entre outros aspectos, ao desenvolvimento inicial mais rápido em comparação às leguminosas. Porém, é preciso fazer uma ressalva para o sorgo, que apesar de ser uma gramínea tropical de via fotossintética $\mathrm{C}_{4}$ como o milheto (TESAR, 1984), seu crescimento inicial foi muito lento, com baixa produção de matéria vegetal aos 30 DAS (Tabela 1).

As máximas produtividades de fitomassa aos 30 DAS foram alcançadas pelo milheto consorciado ao guandu-anão e ao sorgo (Tabela 1). Ou seja, no monocultivo de milheto, no espaçamento entrelinhas de $0,40 \mathrm{~m}$, a forte competição intraespecífica inibiu consideravelmente o crescimento inicial das plantas. Por outro lado, na competição interespecífica, com os consórcios de milheto + guandu-anão e milheto + sorgo, a semeadura intercalar de uma gramínea de maior taxa de crescimento inicial, com outras espécies de crescimento relativamente mais lento (guanduanão e sorgo), pode ter favorecido o crescimento do milheto (Tabela 1), o que acarretou em um expressivo incremento de produtividade de palhada em curto e médio prazos (30 e 60 DAS).

Portanto, cultivos consorciados envolvendo espécies de crescimento inicial relativamente lento, como o guandu-anão e o sorgo, em associação a outras de alta capacidade de cobertura do solo como o milheto, dependendo das condições edafoclimáticas e de manejo, provavelmente resultarão em plantas dominadas por parte das espécies mais lentas, desfavorecendo o equilíbrio na constituição da palhada e prejudicando os benefícios almejados para a cultura de cobertura consorciada.

É preciso considerar também que o rendimento e a composição da matéria vegetal das culturas de cobertura do presente trabalho, podem ter sido influenciados pela adubação de semeadura com 200 $\mathrm{kg} \mathrm{ha}{ }^{-1}$ do fertilizante formulado 08-28-16, principalmente como possível justificativa para o forte crescimento inicial do milheto (Tabela 1), em razão de respostas geralmente expressivas de gramíneas à adubação nitrogenada (CANTARELla et al. (1997). Porém, devido ao delineamento experimental utilizado, é impossível discutir os efeitos da adubação sobre os resultados alcançados.

A adubação empregada no trabalho foi calculada com base na recomendação de Cantarella et al. (1997) para a cultura do sorgo, estimando-se um nível de produtividade de 30 a $40 \mathrm{t} \mathrm{ha}^{-1}$ de matéria verde. Considerando-se um teor de água médio na parte aérea de gramíneas 
como o sorgo da ordem de $70 \%$, por ocasião da colheita para silagem, a produtividade de fitomassa seca superior a $8.000 \mathrm{~kg} \mathrm{ha}^{-1}$ alcançada no presente estudo (Tabela 1), para o monocultivo do sorgo e nos consórcios de sorgo + milheto e sorgo + guandu-anão, estaria compatível com a recomendação de adubação supracitada.

Menezes e Leandro (2004) e Suzuki e Alves (2006) constataram que uma das principais vantagens do milheto é a sua elevada capacidade de superar as plantas daninhas, mesmo em condições de acentuada deficiência hídrica, favorecendo sobremaneira o manejo em áreas em SPD. Em contrapartida, BERTIN et al. (2005) verificou que o milheto cresceu menos que a crotalária júncea, o feijão-de-porco e o lablabe aos 15 e 30 DAS, ainda que, aos 45 DAS tenha superado expressivamente as leguminosas.

Tabela 1. Fitomassa seca produzida em monocultivos e consórcios de guandu-anão, milheto e sorgo cortados aos 30 , 60 e 90 dias após a semeadura (DAS)

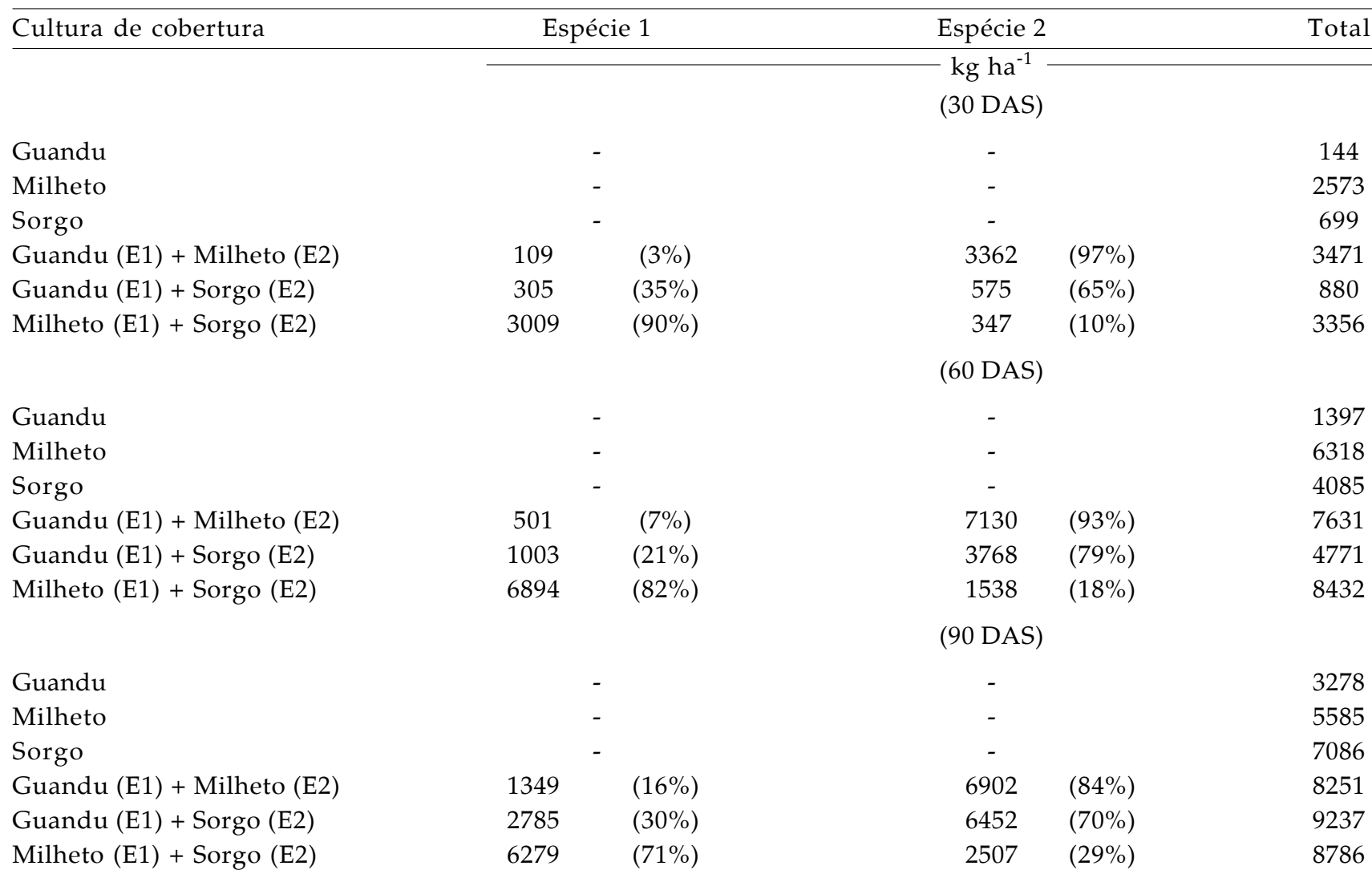

\begin{tabular}{|c|c|c|c|c|c|c|c|c|}
\hline \multirow[t]{2}{*}{ Cultura de cobertura } & \multicolumn{3}{|c|}{30 DAS } & \multicolumn{3}{|c|}{60 DAS } & 90 DAS & Média \\
\hline & 144 & c & B & 1397 & $\mathrm{e}$ & B & $3277 \mathrm{~d} \quad \mathrm{~A}$ & 1606 \\
\hline Milheto & 2573 & $a b$ & B & 6317 & $\mathrm{bc}$ & A & 5584 с $\mathrm{A}$ & 4825 \\
\hline Sorgo & 699 & bc & $\mathrm{C}$ & 4084 & $\mathrm{~d}$ & $\mathrm{~B}$ & 7086 bc A & 3956 \\
\hline Guandu + Milheto & 3471 & $\mathrm{a}$ & B & 7631 & $a b$ & A & $8251 \mathrm{ab}$ & 6451 \\
\hline Guandu + Sorgo & 880 & bc & $\mathrm{C}$ & 4771 & $\mathrm{~cd}$ & B & 9237 a & 4963 \\
\hline Milheto + Sorgo & 3356 & $\mathrm{a}$ & B & 8432 & $\mathrm{a}$ & A & 8786 ab A & 6858 \\
\hline Média & 1854 & & & 5439 & & & 7037 & - \\
\hline
\end{tabular}

E1: guandu e milheto na consorciação. E2: milheto e sorgo na consorciação. Porcentagens entre parênteses representam as quantidades de fitomassa de cada espécie em relação ao total produzido nas lavouras consorciadas. Médias seguidas pelas mesmas letras são iguais estatisticamente pelo teste Tukey a 5\% de probabilidade. Letras minúsculas comparam médias nas colunas e maiúsculas nas linhas. 
TEIXEIRA et al. (2005) também estudaram a consorciação de milheto + guandu-anão e constataram que a leguminosa pouco contribuiu para a produção de palhada em relação à gramínea, corroborando os resultados do presente experimento (Tabela 1). Não é possível, porém generalizar que gramíneas tropicais são mais rápidas no acúmulo de matéria vegetal do que as leguminosas de cobertura, pois TeIXEIRA et al. (2005) observou que no consórcio de milheto + feijãode-porco a produção de fitomassa desta segunda leguminosa foi praticamente igual à da gramínea.

Aos 60 DAS, os destaques de produção de fitomassa, no presente estudo, foram para os consórcios envolvendo o milheto (Tabela 1), caracterizando a superioridade desta gramínea na cobertura do solo no ambiente de safrinha em regiões tropicais. É preciso enfatizar também que aos 60 DAS o rendimento de matéria vegetal do milheto foi significativamente maior nas culturas consorciadas do que no monocultivo, evidenciando o efeito negativo da competição intraespecífica para esta espécie, no espaçamento entrelinhas de $0,40 \mathrm{~m}$, em comparação aos consórcios com guandu-anão e sorgo de crescimento inicial relativamente mais lento (Tabela 1).

Por outro lado, ainda aos 60 DAS, observouse no consórcio sorgo + guandu-anão um pouco mais de equilíbrio em termos de participação de ambas as espécies na formação da palhada, com produtividade de fitomassa seca da ordem de $4.771 \mathrm{~kg} \mathrm{ha}^{-1}$, sendo $21 \%$ provenientes do guandu-anão e $79 \%$ do sorgo. Portanto, esses resultados evidenciam que é preciso haver melhor sincronismo entre as taxas de crescimento das espécies que compõem as culturas de cobertura consorciadas, para que se possa alcançar uma composição de palhada mais balanceada.

No experimento de Perin et al. (2004), com plantas coletadas aos 68 DAS, constatou-se que na consorciação de milheto + crotalária júncea, a leguminosa contribuiu com $65 \%$ da produção final de palhada e proporcionou um incremento de $13 \%$ na produtividade de fitomassa em relação ao monocultivo de milheto. Ou seja, ao contrário do que foi observado para o guandu-anão no presente estudo e no trabalho de Teixeira et al. (2005), outras leguminosas de cobertura tiveram crescimento compatível ou superior ao do milheto, em cultivos consorciados.

Aos 90 DAS, as produtividades de fitomassa dos consórcios envolvendo o milheto ainda foram significativamente superiores às dos demais tratamentos de monocultivo, porém, foram equivalentes ao rendimento de matéria vegetal proporcionado pelo sorgo + guandu-anão (Tabela 1).
O milheto praticamente não acumulou fitomassa quando passou do estádio de 60 para 90 DAS, independentemente de ser em monocultivo ou em consórcios (Tabela 1). Por outro lado, observou-se no consórcio entre sorgo e guandu-anão aos 90 DAS forte aumento na produção vegetal, em relação ao corte realizado aos 60 DAS.

Segundo revisão de NetTo e Bonamigo (2005), o milheto é bastante sensível ao fotoperíodo de dias curtos, ou seja, no fim do verão e início do outono, com a redução do comprimento dos dias, há indução floral e as plantas de milheto entram na fase reprodutiva. No presente experimento, entre 45 e 50 DAS (período que coincidiu com o fim de abril), praticamente em $50 \%$ das plantas de milheto havia as panículas expostas. Assim, a justificativa para a estagnação da produção de fitomassa do milheto na última época de corte, é que as plantas estavam em fase final de enchimento de grãos, com as folhas visivelmente em plena senescência.

Por outro lado, o guandu-anão, leguminosa de crescimento indeterminado (CALEGARI, 1995), e o sorgo, cuja cultivar utilizada no presente trabalho é considerada de menor sensibilidade à variação de fotoperíodo (MAGALHÃES et al., 2006), tiveram ganhos expressivos de produtividade de matéria vegetal em relação ao milheto aos 90 DAS, pois, muito provavelmente houve um período relativamente maior de crescimento vegetativo (Tabela 1). Resultados semelhantes foram demonstrados por LAMAS (2007), com semeadura de espécies de cobertura no início de março e amostragem de fitomassa em julho no centrooeste brasileiro, onde o consórcio guandu + sorgo superou o consórcio guandu + milheto.

O monocultivo de guandu-anão foi o tratamento que resultou no menor rendimento de fitomassa seca no presente estudo, com produtividade máxima de $3.278 \mathrm{~kg} \mathrm{ha}^{-1}$ alcançada aos 90 DAS (Tabela 1). No experimento de TeIXeIRA et al. (2005), com espécies de cobertura semeadas em março, em Lavras (MG), obteve-se resultado ainda inferior para o monocultivo do guandu-anão, com produtividade de apenas $676 \mathrm{~kg} \mathrm{ha}^{-1}$ de matéria seca aos 60 dias após a emergência da cultura. Os autores argumentam que o baixo desempenho desta leguminosa no outonoinverno do sudeste brasileiro pode estar relacionado à ocorrência de baixas temperaturas, que comprometem seu crescimento vegetativo, pois as temperaturas médias ideais para o desenvolvimento do guandu-anão estão entre 20 e $30^{\circ} \mathrm{C}$ (CALEGARI, 1995).

BORKERT et al. (2003) coletaram amostras durante seis anos em diversos experimentos e obtiveram rendimentos de guandu entre 1.390 e 12.190 
$\mathrm{kg} \mathrm{ha}^{-1}$ de fitomassa seca, e relataram que esta leguminosa pode alcançar facilmente produtividades de matéria seca acima de $10.000 \mathrm{~kg} \mathrm{ha}^{-1} \mathrm{em}$ monocultivos, desde que haja boa fertilidade do solo e condições climáticas adequadas.

Amabile et al. (2000) testaram três épocas de semeadura para o guandu na região do cerrado brasileiro, sendo 12 de novembro, 7 de janeiro e 4 de março, e obtiveram produtividades médias de 12.655, 11.142 e $5.753 \mathrm{~kg} \mathrm{ha}{ }^{-1}$ de fitomassa seca respectivamente. Os autores concluíram que ocorre acentuada redução no rendimento de fitomassa desta leguminosa à medida que se atrasa a semeadura e se avança no outono-inverno. Assim, os resultados deste trabalho estão em consonância com outros da literatura, e evidenciam que o guandu-anão, no que diz respeito à produção de palhada, tem baixa aptidão para monocultivos no ambiente de safrinha do Brasil Central.

Observa-se na tabela 2 que, aos 60 DAS, nas palhadas produzidas nos consórcios de milheto + guandu-anão e milheto + sorgo ocorreram os maiores acúmulos de $\mathrm{N}$, da ordem de 146 e $130 \mathrm{~kg} \mathrm{ha}^{-1}$ do nutriente respectivamente. Portanto, considerando-se que na segunda época de corte o milheto intercalado ao guandu-anão e ao sorgo contribuiu com $93 \%$ e $82 \%$ de rendimento de matéria seca vegetal, respectivamente, do total de fitomassas produzidas nos consórcios (Tabela 1), deduz-se que o expressivo incremento na extração de $\mathrm{N}$ deveu-se principalmente ao grande crescimento inicial do milheto até 60 DAS.

Tabela 2. Teor e acúmulo de $\mathrm{N}$, e relação $\mathrm{C} / \mathrm{N}$ de fitomassas produzidas em monocultivos e consórcios de guanduanão, milheto e sorgo cortados aos 30, 60 e 90 dias após a semeadura (DAS)

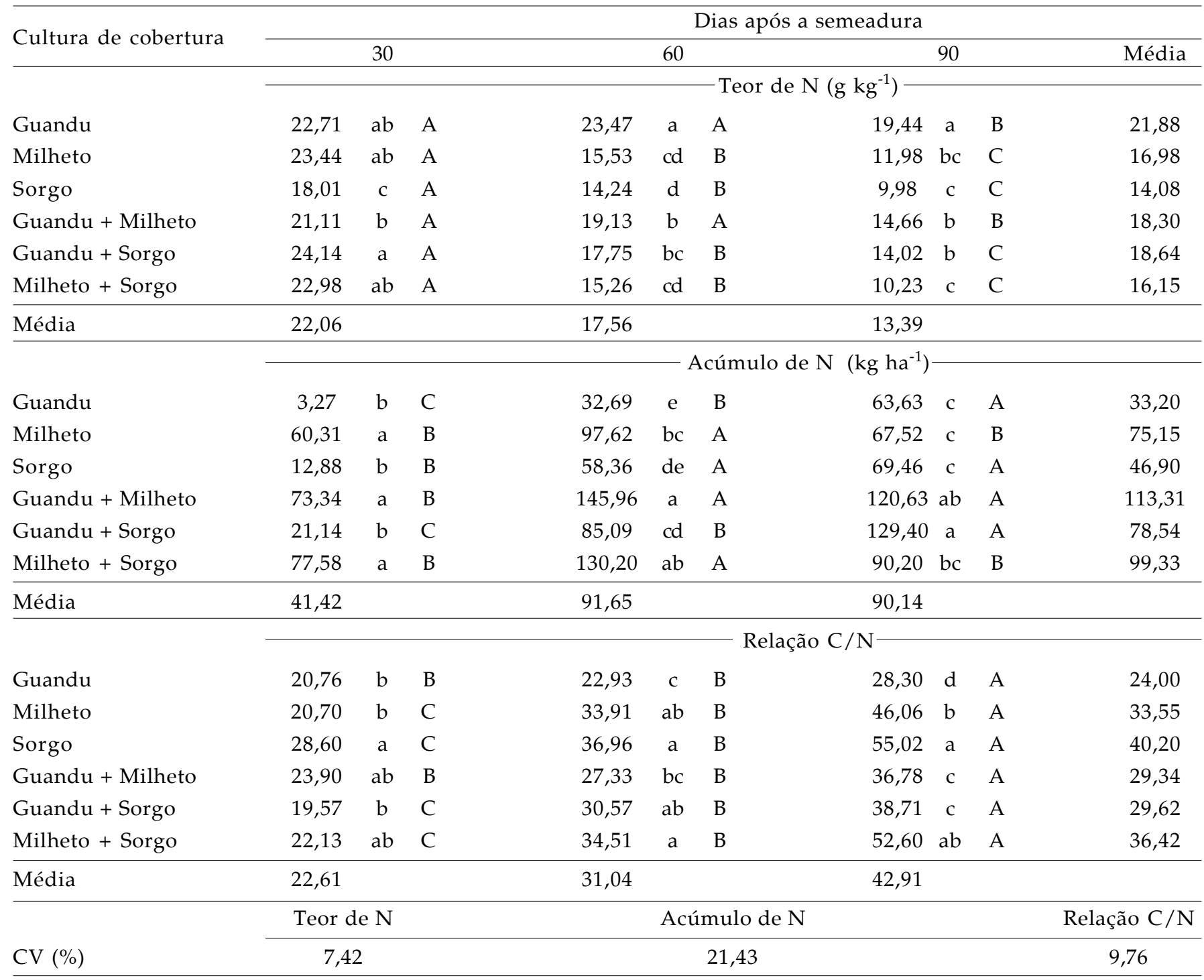

Médias seguidas pelas mesmas letras são iguais estatisticamente pelo teste Tukey a $5 \%$ de probabilidade. Letras minúsculas comparam médias nas colunas e maiúsculas nas linhas. 
Segundo Pereira Filho et al. (2005), o milheto quando utilizado como planta de cobertura, tem alta eficiência para reciclar nutrientes, imobilizando na palhada nutrientes que estavam contidos em camadas relativamente profundas do solo. Os resultados do presente experimento indicam que há forte relação entre potencial de crescimento inicial e eficiência de absorção de $\mathrm{N}$ do solo (Tabelas 1 e 2).

Por outro lado, no corte tardio aos 90 DAS, o consórcio de sorgo + guandu-anão ficou entre os melhores em termos de aporte de $\mathrm{N}$ na palhada (Tabela 2). Novamente, o destaque foi para a espécie com o maior incremento de fitomassa no período, ou seja, aos 90 DAS, o melhor desempenho em termos de rendimento de fitomassa foi para o sorgo no consórcio sorgo + guandu-anão, contribuindo com $70 \%$ do total de palhada produzida no último estádio de avaliação (Tabelas 1 e 2).

Braz et al. (2004) estimaram acúmulos de $\mathrm{N}$ na palhada do milheto de até $348 \mathrm{~kg} \mathrm{ha}^{-1}$, mostrando a grande capacidade desta gramínea em extrair N do solo. CAzETTA et al. (2005) coletaram espécies de cobertura aos 60 dias após a emergência, e constataram que a crotalária júncea, o milheto e o consórcio crotalária júncea + milheto, produziram $5.270,10.673$ e $8.455 \mathrm{~kg} \mathrm{ha}^{-1} \mathrm{de}$ fitomassa seca, e acumularam na palhada 137, 265 e $204 \mathrm{~kg} \mathrm{ha}^{-1}$ de $\mathrm{N}$ respectivamente. Os autores concluíram que a gramínea de cobertura, por sua maior capacidade de produção de fitomassa em curto prazo, conseguiu extrair mais $\mathrm{N}$ por unidade de área, em comparação à leguminosa.

A disponibilização do $\mathrm{N}$ da cultura de cobertura para as lavouras comerciais depende não somente da quantidade de $\mathrm{N}$ acumulada na palhada, mas também da relação $\mathrm{C} / \mathrm{N}$ dos resíduos vegetais produzidos, entre outros fatores (SILGRAM e SHEPHERD, 1999). Nesse contexto, Oliveira et al. (2002) e Aita (1997) definem como palhada ideal para a cobertura do solo no SPD, aquela cuja taxa de decomposição da fitomassa produzida seja compatível com a conservação do solo, protegendo-o contra agentes erosivos por maior tempo possível, e que também disponibilize $\mathrm{N}$ com o máximo de sincronismo em relação às demandas nutricionais das culturas comerciais em sucessão.

Em uma avaliação geral para o guanduanão no monocultivo, houve baixa produção de fitomassa em todas as épocas de corte (Tabela 1), o que comprometeu expressivamente o acúmulo de $\mathrm{N}$ na palhada, apesar dos teores de $\mathrm{N}$ desta leguminosa no monocultivo terem sido significativamente superiores aos dos demais tratamentos, aos 60 e 90 DAS, provavelmente devido à elevada capacidade de fixação biológica de $\mathrm{N}_{2}$ (CALEgARI, 1995). No entanto, o guandu-anão influenciou a composição da relação $\mathrm{C} / \mathrm{N}$ das palhadas produzidas nos consórcios com as gramíneas de cobertura, com reduções significativas nos valores de $\mathrm{C} / \mathrm{N}$ aos 60 e 90 DAS (Tabela 2).

Aos 60 DAS, as relações $\mathrm{C} / \mathrm{N}$ das palhadas de milheto e de sorgo nos monocultivos foram de aproximadamente 32 e 37 , respectivamente, e reduzidas para valores de $\mathrm{C} / \mathrm{N}$ da ordem de 27 e 31 nos consórcios de guandu-anão + milheto e guanduanão + sorgo respectivamente (Tabela 2). Aos 90 DAS, as relações $\mathrm{C} / \mathrm{N}$ do milheto e do sorgo nos monocultivos foram de cerca de 46 e 55, respectivamente, e reduzidas para aproximadamente 27 e 39 nas consorciações de guandu-anão + milheto e guandu-anão + sorgo.

Sendo assim, segundo Moreira e Siqueira (2002), a redução da relação $\mathrm{C} / \mathrm{N}$ da palhada do milheto e do sorgo aos 60 e 90 DAS, proporcionada pela consorciação com o guandu-anão, possibilita que a demanda por $\mathrm{N}$ dos microorganismos do solo seja satisfeita mais rapidamente, e o $\mathrm{N}$ seja liberado com maior rapidez no solo, de tal forma que favoreça o suprimento do nutriente para as lavouras subsequentes em crescimento.

\section{CONCLUSÕES}

1. O milheto tem crescimento mais rápido nos primeiros 60 dias após a semeadura, domina o guandu-anão e o sorgo em consórcio e produz mais fitomassa nas culturas consorciadas do que em monocultivo.

2. O corte ou manejo das culturas consorciadas de milheto + guandu-anão e sorgo + guandu-anão, no ambiente de safrinha, deve ser realizado, respectivamente, aos 60 e 90 dias após a semeadura.

3. Na consorciação de sorgo + guandu-anão há maior sincronismo de crescimento entre ambas as espécies, o que favorece o equilíbrio na composição da fitomassa da cultura de cobertura.

4. Nos consórcios de guandu-anão com as gramíneas ocorrem maiores acúmulos de $\mathrm{N}$ nas palhadas do que no monocultivo de guandu-anão, e menores valores de relação $\mathrm{C} / \mathrm{N}$ em relação aos monocultivos de milheto e sorgo. 


\section{REFERÊNCIAS}

AITA, C. Dinâmica do nitrogênio no solo durante a decomposição das plantas de cobertura: efeito sobre a disponibilidade de nutrientes para a cultura em sucessão em relação ao pousio invernal. In: FREIS, M.R; DALMOLIN, R.S.D. (Coord.). Atualização em recomendação de adubação e calagem: ênfase em plantio direto. Santa Maria: Editora Pallotti, 1997. p.76-111.

AMABILE, R.F.; FANCELLI, A.L. ; CARVALHO, A.M. Comportamento de adubos diferentes épocas de semeadura e espaçamentos na região dos cerrados. Pesquisa Agropecuária Brasileira, v.35, p.47-54, 2000.

AMADO, T.J.C.; MIELNICZUK, J.; FERNANDES, S.B.V. Leguminosas e adubação mineral como fontes de nitrogênio para o milho em sistemas de preparo do solo. Revista Brasileira de Ciência do Solo, v.24, p.179-189, 2000.

AMBROSANO, E.J.; TANAKA, R.T.; MASCARENHAS, H.A.A. Leguminosas e Oleaginosas. In: van RAIJ et al. (Ed.). Recomendações de Adubação e Calagem para o Estado de São Paulo. 2 ed. Campinas: Instituto Agronômico/Fundação IAC, 1996. p.187-203. (Boletim 100)

ANDREOLA, F.; COSTA, L.M.; OLSZEVSKI, N.; JUCKSCH, I. A cobertura vegetal de inverno e a adubação orgânica e, ou mineral influenciando a sucessão feijão/milho. Revista Brasileira de Ciência do Solo, v.24, p.867-874, 2000.

BERTIN, E.G.; ANDRIOLI, I.; CENTURION, J.F. Plantas de cobertura em pré-safra ao milho em plantio direto. Acta Scientiarum Agronomy, v.27, p.379-386, 2005.

BORKERT, C.M.; GAUDENCIO, C.A.; PEREIRA, J.E. Nutrientes minerais da biomassa da parte aérea em culturas de cobertura do solo. Pesquisa Agropecuária Brasileira, v.38, p.143-153, 2003.

BRAZ, A.J.B.P.; SILVEIRA, P.M.; KLIEMANN, H.J.; ZIMMERMANN, F.J.P. Acumulação de nutrientes em folhas de milheto e dos capins braquiária e mombaça. Pesquisa Agropecuária Tropical, v.34, p.83-87, 2004.

CALEGARI, A. Leguminosas para adubação de verão no Paraná. Londrina, IAPAR, 1995. 118p.

CANTARELLA, H.; RAIJ, B.van; CAMARGO, C.E.O. Adubação de Cereais. In: RAIJ, B. van.; et al. (Eds.). Recomendações de adubação e calagem para o Estado de São Paulo. 2 ed. Campinas: Instituto Agronômico, 1997. p.43-50. (Boletim 100)

CANTARELLA, H.; RAIJ, B.van; SAWAZAKI, E. Adubação do sorgo-granífero, forrageiro e vassoura. In: RAIJ, B. van.; et al. (Eds.). Recomendações de adubação e calagem para o Estado de São Paulo. 2 ed. Campinas: Instituto Agronômico, 1997. p. 66-67. (Boletim 100)

CAZETTA, D. A.; FORNASIERI FILHO, D.; GIROTTO, F. Composição, produção de matéria seca e cobertura do solo em cultivo exclusivo e consorciado de milheto e crotalária. Acta Scientiarum Agronomy, v.27, p.575-580, 2005.
EMBRAPA. Empresa Brasileira de Pesquisa Agropecuária Centro Nacional de Pesquisa de Solos. Manual de métodos de análise de solo. 2.ed. Rio de Janeiro, 1997. 212 p.

EMBRAPA. Sistema brasileiro de classificação de solos. Rio de Janeiro: Embrapa Solos, 1999. 412p.

GIACOMINI, S.J.; AITA, C.; CHIAPINOTTO, I.C.; HÜBNER, A.P.; MARQUES, M.G.; CADORE, F. Consorciação de plantas de cobertura no outono/inverno como fonte de nitrogênio ao milho em sistema plantio direto: II. Potencial de fornecimento de nitrogênio. Revista Brasileira de Ciência do Solo, v.28, p. 751-762, 2004.

LAMAS, F.M. Espécies para cobertura do solo e seus efeitos no algodoeiro. Revista Brasileira de Oleaginosas e Fibrosas, v. 11, p.55-63, 2007.

MAGALHÃES, P.C.; DURÃES, F.O.M.; RODRIGUES, J.A.S. Ecofisiologia do sorgo. In: RODRIGUES, J.A.S.; SANTOS, F.G. (Ed.). Sistema de produção do sorgo. Sete Lagoas: Embrapa, 2006. Disponível em: www.embrapa.br. Acesso em: 8 jan 2006.

MALAVOLTA, E.A.; VITTI, G.C.; OLIVEIRA, S.A. Avaliação do estado nutricional das plantas: princípios e aplicações. Piracicaba: POTAFÓS, 1997. 210p.

MENEZES, L.A.S.; LEANDRO, W. M.. Avaliação de espécies de coberturas do solo com potencial de uso em sistema de plantio direto; Pesquisa Agropecuária Tropical, v.34, p.173$180,2004$.

MOREIRA, F.M.S.; SIQUEIRA, J.O. Microbiologia e bioquímica do solo. Lavras: Editora UFLA, 2002. 626p.

NETTO, D.A.M. A cultura do milheto. Sete Lagoas: EmbrapaCNPMS, 1998. 6p. (Embrapa-CNPMS. Comunicado técnico, 11)

NETTO, D.A.M.; BONAMIGO, L.A. Milheto: característica da espécie e uso. In: NETTO, D.A.M.; DURÕES, F.O.M. (Eds.). Milheto: tecnologias de produção e agronegócio. Brasília: Embrapa-Informações tecnológicas, 2005. p.17-33.

OLIVEIRA, F.H.T.; NOVAIS, R.F.; ALVAREZ V., V.H.; CANTARUTTI, R.B.; BARROS, N.F. Fertilidade do solo no sistema plantio direto. Tópicos em ciência do solo. Viçosa: SBCS, 2002. v.2, p.434-464.

PEREIRA-FILHO, I.A.; RODRIGUES, J.A.S.; KARAM, D.; COELHO, A.M.; ALVARENGA, R.C.; CRUZ, J.C.; CABEZAS, W.L. Manejo da cultura do milheto. In: NETTO, D.A.M.; DURÕES, F.O.M. (Eds.). Milheto: tecnologias de produção e agronegócio. Brasília: Embrapa-Informações tecnológicas, 2005. p.59-87.

PERIN, A.; SANTOS, R.H.S.; URQUIAGA, S. Produção de fitomassa, acúmulo de nutrientes e fixação biológica de nitrogênio por adubos verdes em cultivo isolado e consorciado. Pesquisa Agropecuária Brasileira, v. 39, p.3540, 2004 .

PIMENTEL, C. Metabolismo de carbono na agricultura tropical. Rio de Janeiro: EDUR, 1998.159p. 
PORTUGAL, A.F.; ROCHA, V.S.; SILVA, A.G.; PINTO, G.H.F.; PINA-FILHO, O.C. Fenologia de cultivares de sorgo no período de verão e rebrota na safrinha. Revista Ceres, v.50, p.325-336, 2003.

RAIJ, B. van.; ANDRADE, J.C.; CANTARELLA, H.; QUAGGIO, J.A. Análise química para avaliação da fertilidade de solos tropicais. Campinas: IAC, 2001. 284p.

RIBAS, P.M., Implantação da cultura. In: RODRIGUES, J.A.S.; SANTOS, F.G. (Ed.). Sistema de produção do sorgo. Sete Lagoas: Embrapa, 2006. Disponivel em: www.embrapa.br, Acesso em: 08 jan. 2006.

SILGRAM, M.; SHEPHERD, M. A. The effects of cultivation on soil nitrogen mineralization. Advance Agronomy, v.65, p. 267311, 1999.

SUZUKI, L.E.A.S.; ALVES, M.C. Fitomassa de plantas de cobertura em diferentes sucessões de culturas e sistemas de cultivo. Bragantia, v.65, p.121-127, 2006.

TAIZ, L.; ZEIGER, E. Plant physiology. 3. ed. Sunderland: Sinauer Associates, 2002. 290p.

TEDESCO, M. J.; GIANELLO, C.; BISSANI, C. A.; VOLKWEISS, S. J.; BOHNEN, H. Análises de solo, planta e outros materiais. 2. ed. Porto Alegre: UFRGS, 1995. 174p.

TEIXEIRA, C.M.; CARVALHO, G.J.; NETO, A.E.F.; ANDRADE, M.J.B.; MARQUES, E.L.S. Produção de biomassa e teor de macronutrientes do milheto, feijão-de-porco e guandu-anão em cultivo solteiro e consorciado. Ciência e Agrotecnologia, v.29, p.93-99, 2005.

TESAR, M. B. Physiological basis of crop growth and development. Madison: American Society of Agronomy, 1984. $341 \mathrm{p}$. 